Vol. 1, No. 2, 2019

\title{
IMPLEMENTASI IOT PADA PENANGANAN LISTRIK PADAM MENGGUNAKAN MIKROKONTROLLER
}

\author{
Yulistya Trinowanda Gita ${ }^{1}$, Anggri Sartika Wiguna ${ }^{2}$, Wahyudi Harianto ${ }^{3}$ \\ Prodi Teknik Informatika, Universitas Kanjuruhan Malang ${ }^{1,2,3}$ \\ gitayulistya@gmail.com¹ ${ }^{1}$,anggrisartikawiguna@unikama.ac.id², Wahyudi@unikama.ac.id ${ }^{3}$
}

\begin{abstract}
Abstrak. Masyarakat saat ini mengalami banyak peningkatan terhadap kebutuhan konsumsi energi listrik, namun ada kalanya dilakukan pemeliharaan trafo distribusi tersebut artinya listrik yang didistribusikan ke pelanggan akan padam dengan waktu cukup lama. Lama penggantian trafo distribusi dibutuhkan waktu yang cukup lama, antara 4 sampai 5 jam tergantung lokasi penggantian trafo distribusi tersebut. Dengan demikian kWh listrik tidak dapat terjual dengan maksimal dan pelayanan kepada pelanggan jadi terganggu.

Disisi lain pelanggan akan merasa kecewa karena lisrik yang dinikmati sedang dipadamkan karena ada pemeliharaan trafo distribusi. Dan juga PT PLN (Persero) tidak dapat menjual listrik dengan maksimal, maka sebuah sistem dirancang untuk melimpahkan beban trafo distribusi yang padam ke trafo distribusi lainnya yang tidak mengalami pemadaman. Artinya pelanggan yang harusnya merasakan pemadaman listrik masih dapat menikmati pasokan listrik dan $\mathrm{kWh}$ listrik tetap terjual dengan baik. Dan dengan adanya alat ini dapat mengetahui dengan cepat trafo distribusi mana yang mengalami padam tanpa menunggu adanya laporan dari pelanggan bahwa listrik mengalami padam.
\end{abstract}

Kata Kunci: Low Voltage Circiut Breaker; Website; Short Message Service; PT PLN (Persero)

\section{PENDAHULUAN}

Di era seperti saat ini masyarakat mengalami banyak peningkatan terhadap kebutuhan konsumsi energi listrik. Energi listrik merupakan salah satu kebutuhan manusia yang sangat penting dan vital yang tidak dapat dilepaskan dari keperluan sehari-hari. Manusia hampir tidak dapat melakukan pekerjaan yang ada dengan baik ataupun memenuhi kebutuhannya. Sehingga PT PLN (Persero) selaku produsen energi listrik berusaha mengimbangi kebutuhan tersebut dengan selalu menambah pasokan tenaga listrik, hanya saja PT PLN (Persero) mengalami keterlambatan dalam membangun pengembangan jaringan listrik dan ketersediaan listrik tidak sebanding dengan peningkatan permintaan. Sehingga pada saat banyak permintaan maka daya yang ada harus dibagi, dan sering terjadi pemadaman listrik secara bergantian. Dampak dari permasalahan membuat PT PLN (Persero) memerlukan investasi baru untuk peningkatan pasokan energi listrik, sehingga menyebabkan tarif dasar listrik perlu dinaikkan. Akan tetapi, ada beberapa cara untuk sedikit mengatasi permasalahan tersebut dengan memaksimalkan peralatan yang ada sekarang ini.

Internet of Things atau yang sering disebut IOT adalah sebuah konsep yang memiliki tujuan memperluas manfaat dari konektivitas internet yang tersambung secara terus-menerus. Melalui internet bisa melakukan berbagi data, remot kontrol, dan berbagai hal. Termasuk untuk membuat sistem pengendalian listrik dari trafo distribusi agar dapat bekerja dengan maksimal dan dapat mengatasi masalah listrik padam. IOT disini nantinya akan mengontrol mikrokontroller yang sudah terpasang pada gardu trafo distribusi. 
Gangguan dalam pendistribusian listrik PLN dapat terjadi dikarenakan banyak hal. Selain padam karena gangguan karena alam, gangguan karena binatang, gangguan karena pohon, juga banyak gangguan karena trafo distribusi mengalami kerusakan. Selama ini kondisi trafo distribusi harus selalu dimonitor agar tidak mengalami kerusakan dan dapat berusia lebih panjang. Jadi, apabila trafo distribusi mengalami kerusakan maka harus dilakukan penggantian trafo distribusi yang memakan waktu cukup lama, sehingga pelanggan tidak dapat menikmati listrik dari PLN. Selain kerusakan trafo distribusi yang dapat mengakibatkan padam listrik cukup lama, pemeliharaan trafo distribusi pun juga harus mengalami padam cukup lama pula. Dengan pemeliharaan trafo distribusi tersebut artinya listrik yang didistribusikan ke pelanggan akan padam. Disisi lain pelanggan akan merasa kecewa karena lisrik yang digunakan sedang dipadamkan karena ada pemeliharaan trafo distribusi.

\section{METODE PENELITIAN}

- Perancangan Diagram Blok Sistem

Sebelum merancang sebuah sistem harus dibuatlah sebuah diagram blok untuk menjelaskan alur dari sistem yang akan dibuat secara keseluruhan, berikut adalah gambar diagram blok sistem, yang ditujukkan oleh gambar 1 .

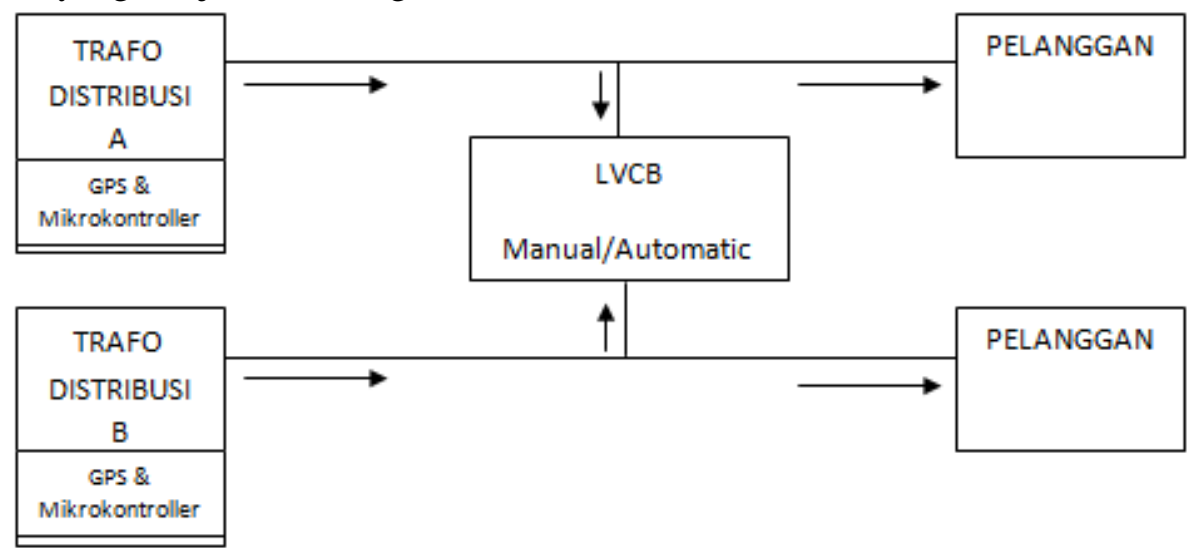

Gambar .1 Diagram Blok Sistem Keseluruhan

- Perancangan Sistem Operasi LVCB

Perancangan sistem LVCB ada 2, yaitu : Pengoperasian Manual dan Pengoperasian Otomatis / Jarak Jauh. Pengoperasian dengan cara manual yaitu dengan membuat rangkaian yang terdiri dari Kontaktor Magnit, Tombol Push Button, dan kabel rangkaian yang dirangkai seperti gambar rangkaian dibawah ini:

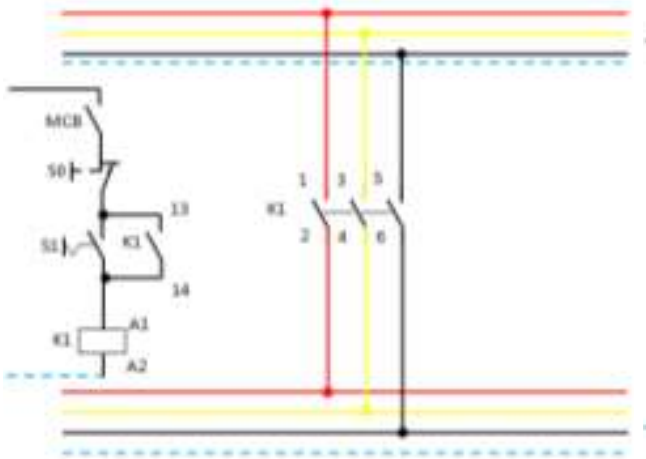

Gambar .2 Rangkaian Kontrol LVCB dengan push button

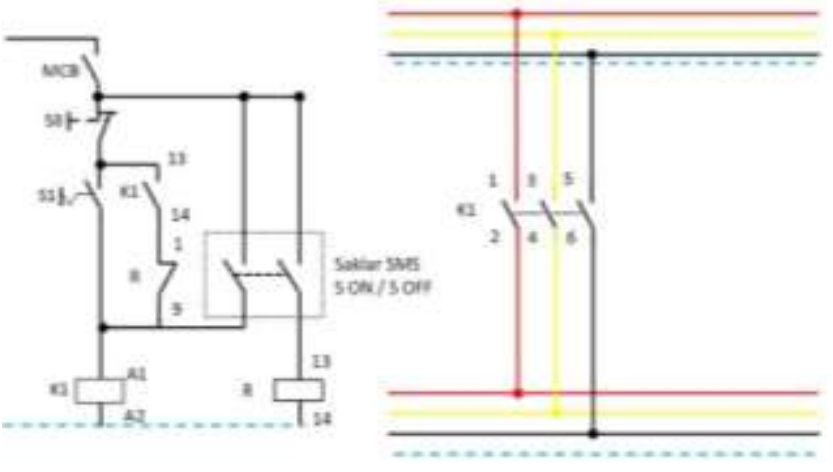

Gambar .3 Rangkaian Kontrol LVCB manual dan jarak jauh menggunakan SMS Gateway 
Perancangan Modul SMS Listrik Padam, Modul SMS Listrik Padam ini akan bekerja pada saat listrik pada gardu mengalami padam. Saat listrik mengalami padam modul yang sudah diprogram akan mengirim pesan singkat kepada operator dan web server.

Berikut rangkaian dari modul SMS Listrik Padam :

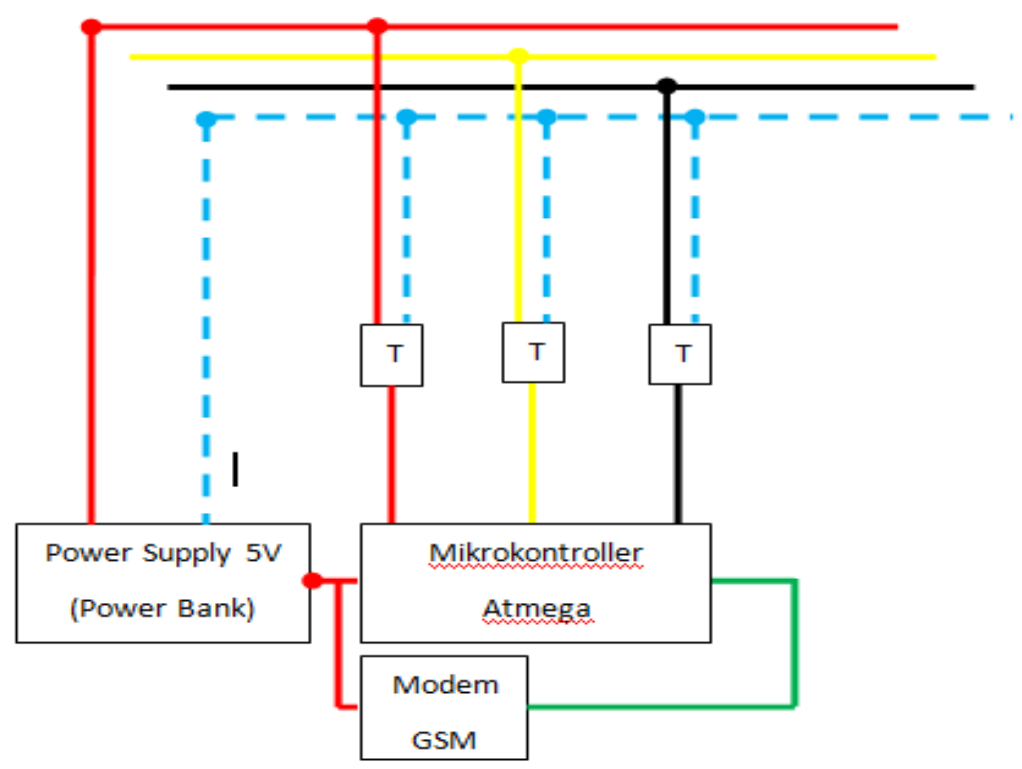

Gambar .4 Rangkaian Modul SMS Lisrik Padam

- Perancangan GPS

Pada sistem ini GPS digunakan untuk mengetahui lokasi terjadinya gangguan trafo distribusi.GPS dipasang pada tiap-tiap trafo distribusi guna percepatan pemadaman akibat gangguan trafo distribusi dan juga untuk mengantisipasi dari pencurian peralatan listrik pada panel trafo distribusi.

- Perancangan Tampilan LCD

Tampilan LCD yang digunakan pada sistem ini adalah tampilan yang menunjukkan besarnya tegangan dan arus yang diletakkan pada kotak panel LVCB. Agar saat akan melakukan proses manuver dapat mengetahui berapa tegangan pada titik manuver/pelimpahan dan untuk memonitor besarnya arus yang dilimpahkan.

- Perancangan Kontaktor Magnit

Kontaktor Magnit yang digunakan adalah Kontaktor Magnit dengan kemampuan menghantarkan arus sebesar 100 Ampere. Sumber tegangan atau catu daya utama kontaktor magnit menggunakan baterai 12 Volt DC yang kemudian dirubah menjadi tegangan 220 Volt AC dengan menggunakan inverter DC to AC. Dengan menggunakan catu daya tersebut sudah dapat mengoperasikan LVCB dengan manual ataupun jarak jauh.

- Perancangan Flowchart pada IoT Menggunakan Mikrokontroller

Perancangan flowchart pada IoT menggunakan mikrokontroller dapat dilihat pada gambar 3.5 berikut. 


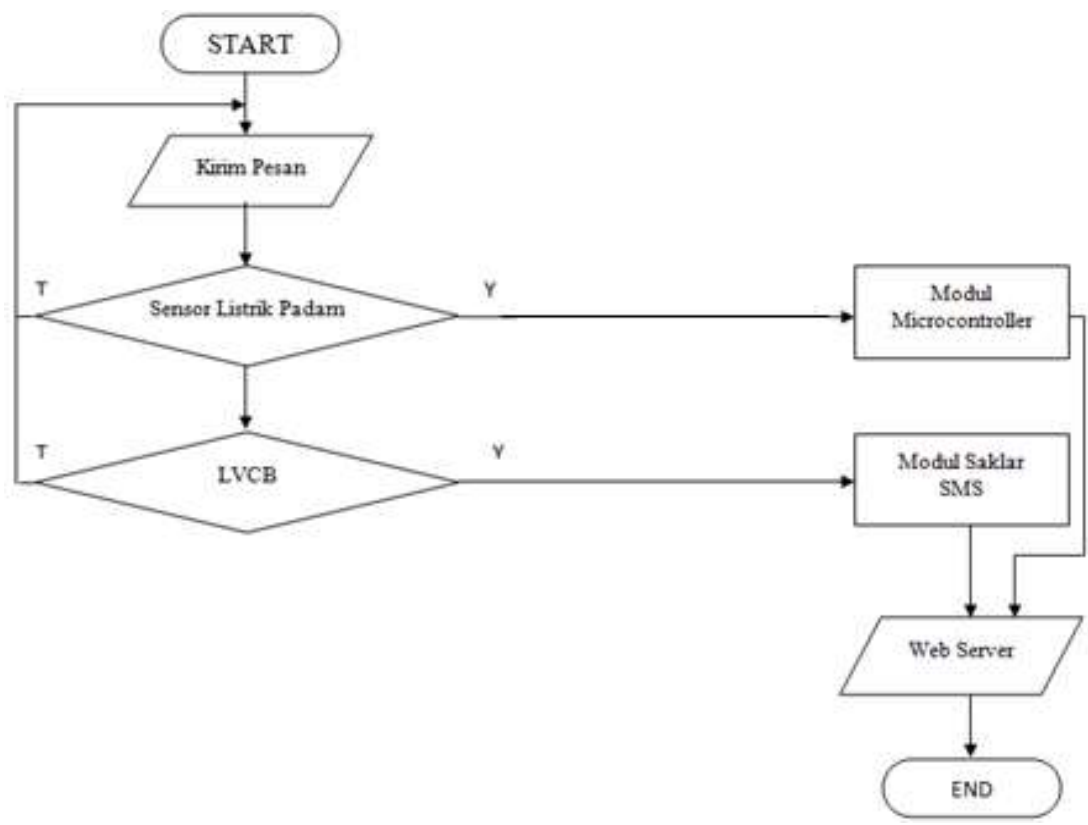

Gambar .5 Perancangan Flowchart menggunakan IoT pada Mikrokontroller

- Perancangan Alat dan Peralatan yang dibutuhkan

Berikut beberapa peralatan yang dibutuhkan untuk merancang alat : Kontaktor Magnit digunakan sebagai LVCB, MCB digunakan sebagai simulasi Gardu Distribusi
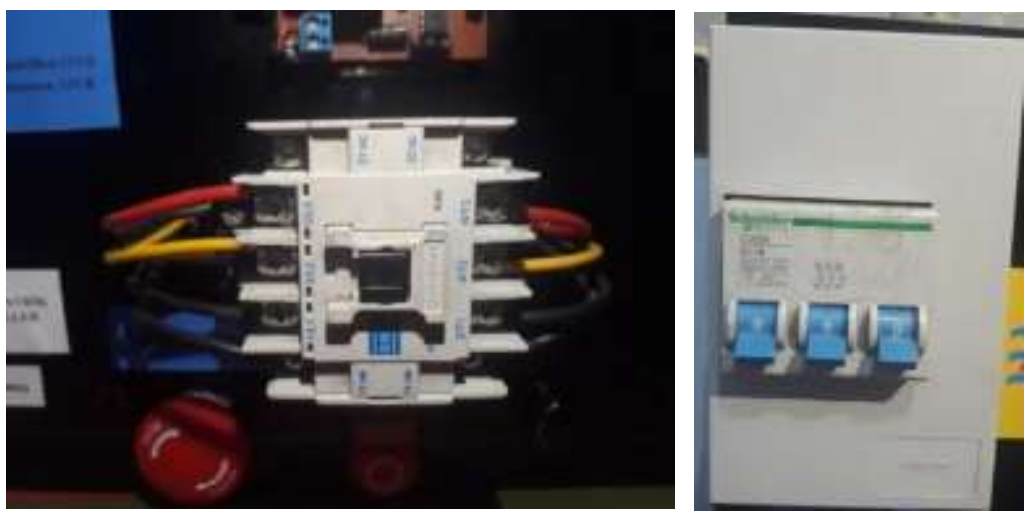

Gambar .6 Kontaktor Magnit dan MCB (Miniatur Circuit Breaker)

Lampu Indikator digunakan sebagai simulasi pelanggan yang dialiri listrik, Tombol manual digunakan untuk mengaktifkan dan mematikan LVCB, Tampilan Tegangan dan Arus digunakan sebagai monitor tegangan dan arus pada LVCB
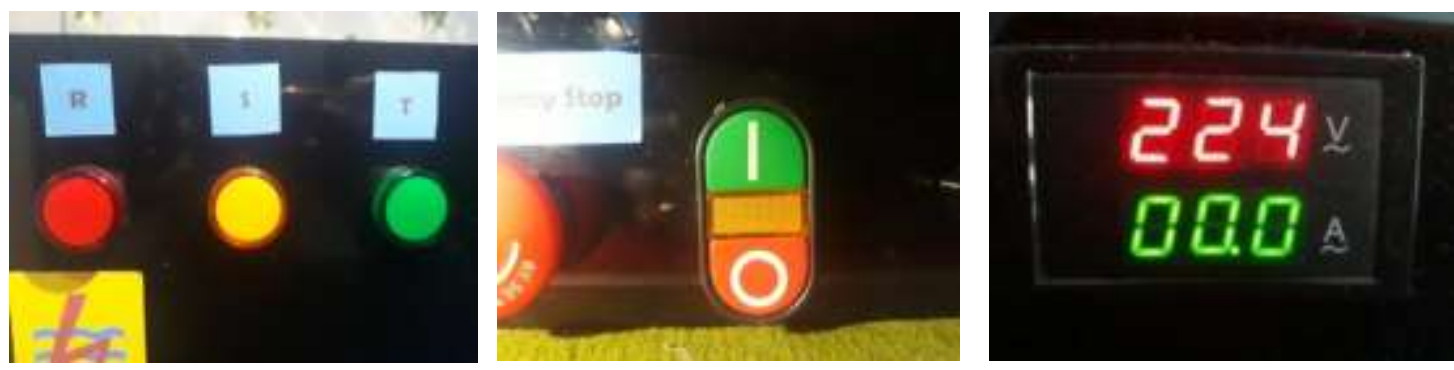

Gambar .7 Lampu Indikator, Tombol Manual dan Tampilan Tegangan dan Arus 
Modul saklar SMS digunakan sebagai alat yang dapat mengaktifkan dan mematikan LVCB melalui SMS, Tombol reset digunakan apabila terjadi error pada rangkaian, Trafo digunakan sebagai sensor tegangan yang masuk pada rangkaian mikrokontroller.
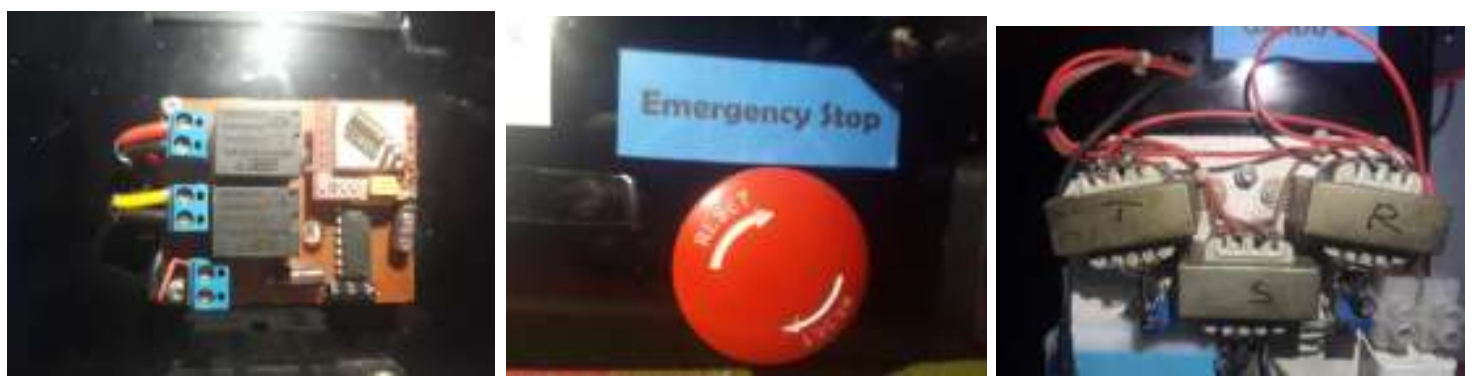

Gambar .8 Modul Saklar SMS, Tombol Reset dan Trafo Stepdown

Rangkaian Mikrokontroller digunakan sebagai modul yang dapat mengirimkan pesan pemberitahuan bahwa listrik mengalami padam, Modem GSM digunakan sebagai pengirim dan penerima pesan yang terhubung dengan mikrokontroller, Relay digunakan sebagai pengunci rangkaian control.
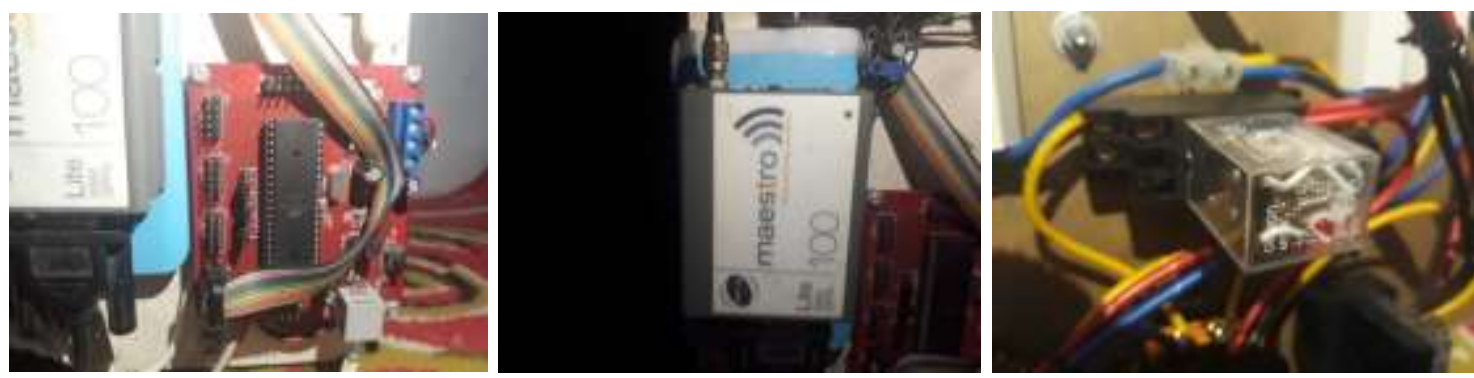

Gambar .9 Rangkain Mikrokontroller, Modem GSM dan Relay

Antena digunakan sebagai pengiat sinyal dari modem GSM, Kabel listrik digunakan untuk merangkai peralatan, Kabel pelangi digunakan untuk menghubungkan keluaran sensor tegangan dengan mikrokontroller.
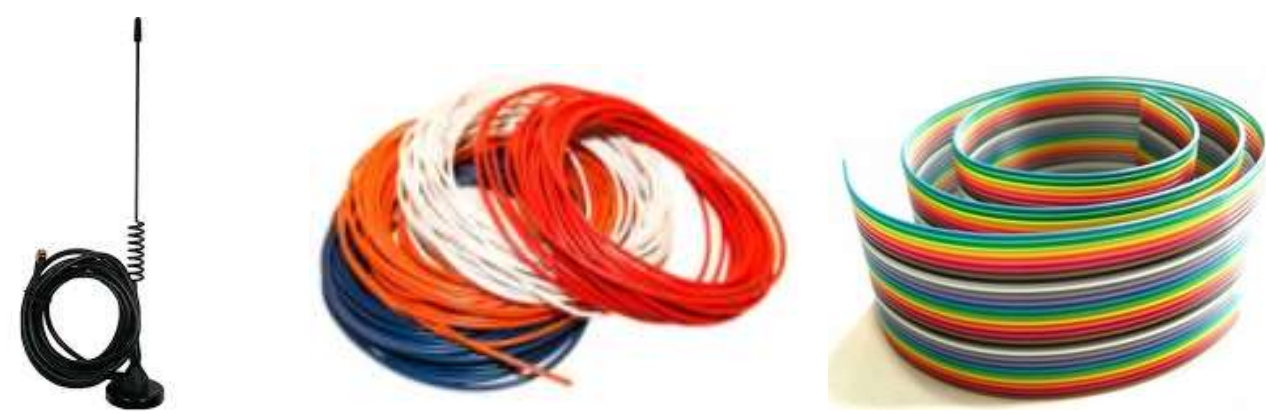

Gambar .10 Antena, Kabel, Kabel Pelangi

Power bank digunakan sebagai sumber utama mikrokontroller dan modem GSM dan Tampilan Simulasi Alat Setelah Dirangkai. 

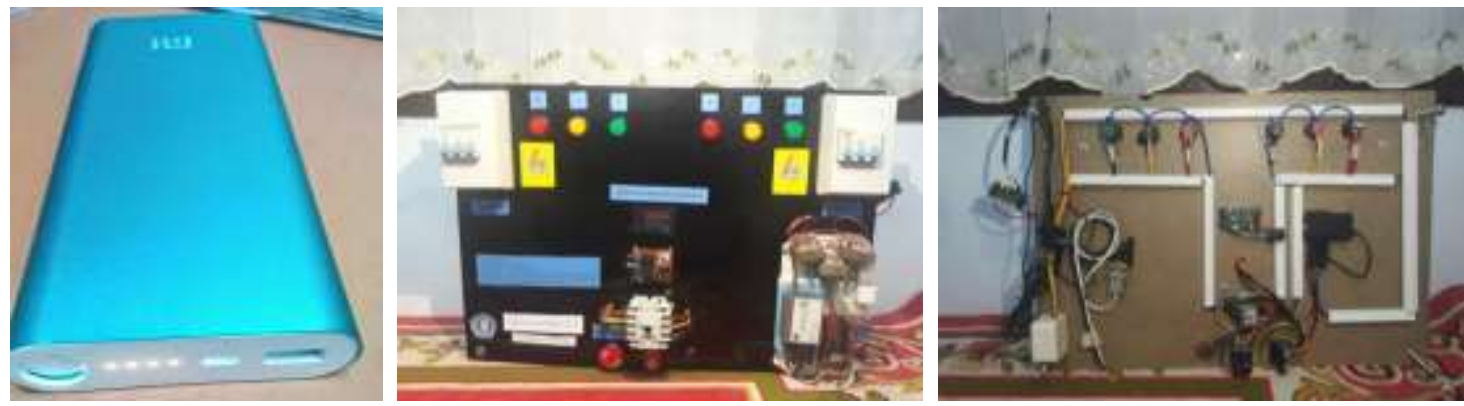

Gambar .11 Power Bank, Hasil Alat Simulasi dan Rangkaian Alat Simulasi

\section{HASIL DAN PEMBAHASAN}

Berdasarkan perancangan alat yang sudah dilakukan perlu dilakukan pengujian dan analisa untuk mendapatkan hasil yang maksimal. Dari pengujian dan analisa ini nantinya akan didapatkan hasil dan evaluasi agar tugas akhir yang ada dalam pembahasan ini dapat dikembangkan lagi. Tujuan Pengujian dan analisa ini dimaksudkan untuk mendapatkan evaluasi terhadap rangkaian, agar diperoleh kinerja yang lebih baik dan dapat dipergunakan secara maksimal. Kinerja yang lebih baik didapatkan dengan melakukan perbaikan terhadap komposisi rangkaian yang mengalami kekeliruan yang diketahui pada saat melakukan pengujian.

LVCB dengan deteksi lokasi berbasis GPS dinyatakan dapat beroperasi dengan baik apabila kerjanya sesuai dengan fungsi yang dikehendaki atau direncanakan saat perancangan. Pengujian LVCB dilakukan pada dua operasi, yaitu operasi manual dan operasi otomatis/jarak jauh. Pengujian dua operasi ini dilakukan untuk memastikan LVCB dapat bekerja pada dua operasi yang diharapkan.

\section{PENUTUP}

Dari hasil pengujian LVCB (Low Voltage Circuit Breaker) di Laboratorium Teknik Informatika adalah sebagai berikut :

1. LVCB yang dirancang dapat mengakomodasi dua operasi transfer atau pemindahan beban yaitu secara manual dan otomatis.

2. Dengan adanya LVCB dan alat deteksi lokasi ini, dapat mempercepat pekerjaan penormalan listrik yang padam.

3. Alat ini dapat bekerja dari jarak jauh.

4. Alat ini dapat diaplikasikan terutama pada lokasi yang sering terjadi padam karna gangguan trafo.

5. Kondisi sinyal sangat berperan penting dalam pengoperasian jarak jauh, tergantung dari lokasi dan provider yang digunakan.

\section{Saran}

Dari perancangan sistem ini, masih ada beberapa kekurangan yang dapat digunakan sebagai acuan untuk penelitian kedepan sehinggan mampu mendapatkan suatu sistem manuver atau pelimpahan beban yang lebih baik dan lebih handal. Dari hasil pengujian sistem, ada beberapa koreksi yang harus lebih diperhatikan.

1. Diharapkan alat ini dapat dimanfaatkan untuk mempercepat dan meminimalisir listrik padam.

2. Untuk penelitian selanjutnya alat ini, diharapkan dapat dikembangkan lagi agar dapat bekerja lebih maksimal lagi.. 


\section{DAFTAR PUSTAKA}

Basuki. 2009. Diktat Kuliah Bahan-bahanListrik. Banda Aceh: Universitas Syiah Kuala.

Blocher, R. 2004.Dasar Elektronika. Yogyakarta: Penerbit Andi Yogyakarta.

Data Pelanggan PT PLN (Persero) Rayon Indrapura, 2 Desember 2017

Siregar, W. 2004.Electrical Utilities. Jakarta: Erlangga.

William D. Stevenson Jr, Kamal Idris. 1994. Analisis Sistem Tenaga Listrik, Edisi Keempat. Jakarta:Erlangga

Zuhal. 1995, Dasar Teknik Tenaga Listrik dan Elektronika Daya. Jakarta:PT.Gramedia Pustaka Utama. 